\title{
Evaluation of Manager's Performance through Stochastic Modelling
}

\author{
P. Tirupathi Rao \\ Department of Statistics, Pondicherry University, Puducherry, India \\ Email: drtrpadi@gmail.com
}

Received September 30, 2012; revised October 28, 2012; accepted November 14, 2012

\begin{abstract}
Decision making is one of the important activities of the managerial problems. Scientific methodology for quantitative techniques is an essential tool in the contemporary decision making protocols. In this paper an attempt is made to develop a stochastic model on manager's performance appraisal. Managerial choice among the available options for decision making is formulated to obtain the stochastic process, to derive the model and to obtain statistical measures. Numerical illustrations are provided for understanding the managerial performance and its evaluation. This study is useful to assess the abilities of an employee by his/her employer. Development of Desktop automations to this study will open a wide spectrum of dynamic Decision Support Systems.
\end{abstract}

Keywords: Stochastic Modelling; Manager's Performance; Management Decision Making

\section{Introduction}

The paradigms of Decision making procedures have transformed from the conventional methods of Logical and Artistic orientation to Scientific and Technological approaches. Traditionally, the decision making is considered to be a discipline of Art which is serving the cause of Research and Academia as science. The combination of Mathematical language with Statistical theme and Computational assisting programs elevated the decision making process as a technology of the current day to day management problems. Hence the managers have to handle the activities of decision making with a concept of managerial engineering. Activities of an organization have to be thoroughly evaluated from time to time. Regular monitoring on and updating the managerial activities is a must to any organization. A suitable interface between the management and the employee is very essential to improve the quality of managerial performance. Performance evaluation is a device to assess the ability of a manager by their managements. The primary goal of a performance evaluation is to provide a quantitative measurement of a component's contribution to the whole system. Quantity of the managerial activity is a measure of the organizational efficiency. It is playing a pivotal role in speculating and computing the growth indicators. Hence, modelling the decision making activity is an absolute need of an organization to get the performance measures of their employees. A healthy management system is a result of the effective performance of its inter- nal managerial setup. We may not come across the same/ similar situations for all decision making issues. It can provide an appraisal protocol between the employee and the employer.

As the job of the manager for decision making is considered to be more uncertain, the performance of a manger may be assessed through a suitable evaluation model. Decision making of the present day's management problems is an embodiment of Stochastic Processes, theory of Probability and other related with mathematical aspects management issues. Hence, measuring the manager's performance through the Modelling is one of the important thrust areas in Management Research methods. The methods of decision making may have manifold objectives. The precision of decision making can be quantified by means of statistical techniques. The amalgamation of Mathematical, statistical and managerial programs became the prime concern of a researcher of decision science. Development of an evaluation format, identification of performance parameters, designing the guide lines for getting feedback, setting up of evaluation schedules etc. are the important activities of management problems.

The computational alternative to simulation for a large class of stochastic management models by involving functions of random variables, were handled to deal the problems like risk analysis [1]. The critical assumption in concurrency control performance modelling were investigated for managerial decision making issues [2]. The Productivity situations of sales members by modelling their sales on periodic evaluation were carried out for 
assessing capability of business activators [3]. Number of mathematical models were suggested to measure the financial performance of economic firms [4]. Benchmark performance for assessing the practices of risk management were developed for evaluating the abilities of the portfolio managers [5]. Hierarchical control frame works were developed to solve performance management problems in distributed computing systems operating in a data centres [6]. Performance appraisal system using multifactorial evaluation model in dealing with appraisal grades were developed and expressed in linguistic terms [7]. Development of Generalised Stochastic Petri Nets (GSPN) model was the breakthrough for performance evaluation in business processes [8]. The experimental driven models with Gaussian approach were developed for data base studies using the online performance analysis [9]. Tele communication service management systems using server models with load dependency were developed to study the database servers with suitable performance models [10]. Simulation based performance evaluation of mobility management schemes using target communication system modeling and traffic modeling was carried out [11].

The computation of manager's performance with conventional methods based on psychometric measures is being used by many researchers. The above research review has given much emphasis on Psychometric approach for measuring the performance of a manager. These approaches have the limitations as they are not supported by proper classical mathematical theories and they are considered to be non-parametric studies. As decision making problems are mostly influenced by uncertainty factors and probabilistic assumptions, development of modelling is more appropriate for measuring the performance of a manager. Even though the philosophy of performance evaluation has been applied in many decision making problems deals with machines, databases, Industries, administrative organizations, etc., very little work has been reported on measuring the performance of manager using mathematical formulations and model based. Computing the performance of a manager through stochastic models is quite rational as these methods are considered to be parametric and justified with competent probability theory. In this study a new approach of quantifying the abilities of a manager in modelled using the probabilistic assumptions.

\section{Methodology}

Consider an environment of managerial decision making where manager should act on more than one task. Each task is having more than one exclusive option of handling the activity, among which one option is suitable for correct handling of the task and the remaining options are not suitable for correct handling of the task. The selection of the suitable option by the manager is through the means of either knowing the correct approach with certainity or by guessing the option on probabilistic ways. The proper selection of option shall benefit the employer, for which the manger deserves the reward. On the other hand the improper choice of decision option may give adverse effect on the organization, for which the employer may face penalty. The manager, during his working time with the organization may perform number of tasks; in each task his decision may be either correct or wrong. Let the manager has performed a finite number of tasks among which some are handled with correct approach and the rest of them are handled with improper approach. The influencing effect of his success or failure can be quantified in terms of any conventional methods of measure. If the abilities of successes or failures of the manager are having some payoff, then the total performance shall be numerical value. In order to formulate the above phenomena in to a model, probabilistic assumptions are being considered and a stochastic model was developed after successful attaining of stochastic processes.

Let a manager has a total number of " $A$ " activities during the period of appraisal " $t$ ". Each activity has " $r$ " number of possible complimentary options from which one is chosen by the manager for his task. While selecting the options, the manager may be either aware about the correct and suitable option or he may select one of the options with pure chance manager. Let " $A_{i}$ " be the number of tasks that are being handled by selecting the option with chance " $p_{i}$ ". Let $p_{i}=1$ when the manager is aware of the correct/suitable decision option for handling the task. Whereas if the manager has selected the option on chance factor, then $p_{i}>0$; and $0<p_{i}<1$.

Let $A_{1}$ be the number of handled tasks by a manager with chance $p_{1}=1$ i.e. he has handled the selection of decision option with certainity. Let $A_{2}$ be the number of handled tasks with chance $p_{2}=1 / 2$; i.e. he has handled the task by selecting the decision option with chance 1/2. Similarly Let $A_{r}$ be the number of handled tasks with chance $p_{r}=1 / r$ by the manager; i.e. he has handled the selection of decision option with chance $1 / r$.

Which implies that $A=\sum_{i=1}^{r} A_{i} ; p_{i}=1 / i$ for $i=1,2, \cdots, r$, $r \leq 1$. Let us further assume that there are no unhandled tasks i.e. the manager has to handle the given tasks and he should not say no to the management for handling any given assigned task to him. The appraisal of the manager's performance is based on the credits/benefits/reward (when the tasks are successfully handled) and debits/risks/penalty (when the tasks are handled with failure). The quantified values for credits and debits are denoted 
by " $C$ " and " $D$ ", where $C>0$ and $D<0$. $C$ and $D$ are real numbers with ranges $-\infty<D<0$ and $0<C<\infty$.

\section{Stochastic Model}

The following are some useful notation while developing the model.

$r$ : number of options that are available to the manager for each activity, where $r \geq 0, r$ is finite and complimentary, among available $r$ options, there is only one option considered to be fit to deal the activity.

$C$ : Positive performance score or credit/reward points for adopting the correct option, $0 \leq C<\infty$. D: Negative performance score or debit/penalty points for adopting the wrong option, $-\infty<D \leq 0$.

$A_{i}$ : Number of activities that are handled with chance of selecting the correct option is $p_{i}=1 / i$ for $i=1,2,3$, $4, \cdots, r$.

$A_{0}$ : Number of activities that are not handled $A_{0}=0$. A: Total number of total activities that are handled by a manager during the period of decision making process. If $A_{1}, A_{2}, A_{3}, \cdots, A_{i}$ tasks are of different types, then $A=\sum_{i=1}^{r} A_{i}$.

Further the tasks are categorized as $A_{1}, A_{2}, A_{3}, \cdots, A_{i}$; $A_{i}$ are the number of activities that are handled by selecting the correct option with chances $1,1 / 2,1 / 3, \cdots, 1 / i$ respectively; $X_{i}$ is the output for correct handling of managerial task on $i^{\text {th }}$ activity; $Y_{i}$ is the output for wrong handling of managerial task on $i^{\text {th }}$ activity;

$Z_{i}=C \cdot X_{i}+D \cdot Y_{i}$ is the score for the $i^{t h}$ activity;

$T=\sum_{i=1}^{r} A_{i} Z_{i}$ is the total score on overall performance of $A$ activities.

Let $X_{i}$ be a random variable obtained as a result of correct handling of a task by selecting the available option with chance $1 / i$; for $i=1,2,3, \cdots, r ; X_{i}=1$, if the randomly chosen managers option for decision making is correct for $i^{\text {th }}$ task; $X_{i}=0$, if the randomly chosen managers option for decision making is wrong for $i^{\text {th }}$ task. The above phenomena represents a stochastic process which yields the discrete random variable

$X_{i}\left\{X_{i}, i=1,2,3, \cdots, r\right\}$. This process has the probability function as $\operatorname{Pr}\left\{X_{i}=1\right\}=1 / i ; \operatorname{Pr}\left\{X_{i}=0\right\}=i-1 / i$. and $\operatorname{Pr}\left\{X_{i}=j\right\}=0$, for $j>1 ; i=1,2,3, \cdots, r-1, r$. The raw moments for the above probability distribution are $E\left[X_{i}\right]^{m}=1 / i$ for all $m \geq 1$.

Let $Y_{i}$ be another random variable obtained as a result of wrong handling of a manager's task by selecting the available managerial option with chance $1 / i$; for $i=1,2,3, \cdots, r$; which the number of activities that are handled by the manager are $=A_{i} ; Y_{i}=1$, if the randomly chosen manager's option for decision making is wrong for $i^{\text {th }}$ task. Whereas $Y_{i}=0$, if the randomly chosen man- ager's option of the decision making is correct for $i^{\text {th }}$ task. Similarly, $Y_{i}$ is a random variable obtained from the stochastic process such that $\left\{Y_{i}, i=1,2,3, \cdots, r\right\}$. This process has the probability function as $\operatorname{Pr}\left\{Y_{i}=0\right\}=1 / i$; $\operatorname{Pr}\left\{Y_{i}=1\right\}=i-1 / i$. and $\operatorname{Pr}\left\{Y_{i}=j\right\}=0 ;$ for $j>1$; $i=1,2,3, \cdots, r-1, r$. The raw moments for the above probability distribution are $E\left[Y_{i}\right]^{n}=(i-1) / i$ for all $n \geq 1$. As the events of getting success or failure are complementary, the Joint probability $P\left(x_{i}, y_{i}\right)=0 ; i=$ 0,1 and $j=0,1$. Hence,

$$
E\left(x_{i}, y_{i}\right)=\sum_{i=0}^{1} \sum_{j=0}^{1} x_{i} y_{i} p\left(x_{i}, y_{i}\right)=0 \text {. }
$$

\section{Statistical Measures on Performance}

While handling a managerial task it is observed that there are two disjoint approaches namely either getting success or getting failure after selecting the managerial option to the given task. Hence the resultant activity of managerial performance can be expressed as the linear combination of both success and failure.

Let $Z_{i}$ be the function of managerial performance score function in handling one task in $i^{\text {th }}$ category, where the option among that group is selected on chance basis with probability $1 / i$. then, The Performance score function on $i^{\text {th }}$ category for one task is $Z_{i}=C \cdot X_{i}+D \cdot Y_{i}$ and the Performance score function on $i^{\text {th }}$ category for $A_{i}$ tasks is

$$
\begin{aligned}
& T_{i}=A_{i} \cdot\left\{C \cdot X_{i}+D \cdot Y_{i}\right\} \\
& i=r, r-1, r-2, \cdots, 3,2,1
\end{aligned}
$$

Let $T$ be the total score on Performance of the manager for handling $A$ tasks, then the performance score function of a manager is defined as

$$
T=\sum_{i=1}^{r} A_{i}\left(C \cdot X_{i}+D \cdot Y_{i}\right)
$$

Method of moments is considered for finding the statistical measures of the proposed model. As the first order non central moment is the Average Performance score of a manager, it is given by $E[T]$.

\section{Average Performance Score:}

The Expected (or overall) Performance score of a manager is

$$
=\sum_{i=1}^{r} N_{i} \frac{1}{i}\{C+D \cdot(i-1)\}
$$

\section{Variability of the Performance:}

The deviation or variation in the performance of a manager is another important statistical measure. This is mostly useful in measuring the consistency of the performance. The variance of the total score is 


$$
V(T)=\sum_{i=1}^{r} \frac{A_{i}^{2}}{i}\left[C^{2}+D^{2}(i-1)\right]-\left(\sum_{i=1}^{r} A_{i}\right)^{2}\left(\frac{C+D(i-1)}{i}\right)^{2}+\sum_{i \neq j=1}^{r} \frac{A_{i} A_{j}}{i^{2}}\left\{C^{2}+D^{2}(i-1)^{2}\right\}
$$

The $3^{\text {rd }}$ Central Moment is

$$
\mu_{3}(T)=2\left[\sum_{i=1}^{r} \frac{A_{i}}{i}\{C+D(i-1)\}\right]\left[\left(\sum_{i=1}^{r} \frac{A_{i}}{i}\{C+D(i-1)\}\right)^{2}-\sum_{i=1}^{r} \frac{A_{i}^{2}}{i}\left\{C^{2}+D^{2}(i-1)\right\}\right]
$$

\section{The Fourth central Moment is}

$$
\begin{aligned}
\mu_{4}(T)= & {\left[\frac{C^{2}+D^{2}(i-1)}{i}\right]^{2}\left(\sum_{i=1}^{r} A_{i}^{4}+\sum_{i \neq j=1}^{r}\left\{A_{i}^{2} \cdot A_{j}^{2}\right\}\right) } \\
& +2\left(\frac{\left\{C^{2}+D^{2}(i-1)^{2}\right\}\left\{C^{2}+D^{2}(i-1)\right\}}{i^{3}}\right)\left(\sum_{i=1}^{r} A_{i}^{2}\right)\left(\sum_{i \neq j=1}^{r}\left\{A_{i} \cdot A_{j}\right\}\right) \\
& +\left(\frac{\left\{C^{2}+D^{2}(i-1)^{2}\right\}}{i^{2}}\right)\left[\sum_{i \neq j \neq l=1}^{r}\left(A_{i}^{2} A_{j}^{2}\right)+\sum_{i \neq j \neq k \neq l=1}^{r}\left(A_{i} A_{j} A_{k} A_{l}\right)\right] \\
& -2\left[\sum_{i=1}^{r} \frac{A_{i}^{2}}{i}\left\{C^{2}+D^{2}(i-1)\right\}+\sum_{i \neq j=1}^{r} \frac{A_{i} A_{j}}{i^{2}}\left\{C^{2}+D^{2}(i-1)^{2}\right\}\right] \\
& \times\left[\sum_{i=1}^{r} \frac{A_{i}}{i}\{C+D(i-1)\}\right]\left[2-3 \sum_{i=1}^{r} \frac{A_{i}}{i}\{C+D(i-1)\}\right]-3\left[\sum_{i=1}^{r} \frac{A_{i}}{i}\{C+D(i-1)\}\right]^{4}
\end{aligned}
$$

The coefficient variation is

$$
\left[\sum_{i=1}^{r} \frac{A_{i}^{2}}{i}\left[C^{2}+D^{2}(i-1)\right]+\sum_{i \neq j=1}^{r} \frac{A_{i} A_{j}}{i^{2}}\left\{C^{2}+D^{2}(i-1)^{2}\right\}-\left(\sum_{i=1}^{r} A_{i}\right)^{2}\left(\frac{C+D(i-1)}{i}\right)^{2}\right]^{\frac{1}{2}}\left[\sum_{i=1}^{r} \frac{A_{i}}{i}[C+D(i-1)]\right]^{-1}
$$

The rest of the statistical measure can be obtained from the above derived four central moments

\section{Numerical Illustrations \& Sensitivity Analysis}

Total expected scores for different values of $i$ (number of options), $C$ (Credit Points), $D$ (penalty points); all $A_{i} \geq 0$, for $j=1,2, \cdots, i$ for calculating the Expected Scores for Manager's Performance in Table 1; The graphs were displayed tin the Figures 1(a)-(d). The Variances of Permformance abilities were calculated and presented in Table 2 and the figures were displayed in Figures 2(a)(d); displayed in Annexures

From the data in Table 1 and Figure 1(a), it is observed that the expected scores of manager's performance are increasing function of the credits. Irrespective of the number of options for each managerial task. Further it is observed that the expected scores are decreasing functions of the number of options for each managerial task, under the assumption of all the categories of tasks are equal i.e. $A_{i}=10 ; i=1,2, \cdots, r$. From the data in
Table 1 and Figure 1(b), it is observed that the credits $(C)$ and penalties $(D)$ are related as $D=-1 / C$; The average performance of manager are increasing functions of credits. The expected performance score of manager is a decreasing function of the number of available options for each task, i.e. $A_{i}=10 ; i=1,2, \cdots, r$. From the data in Table 1 and Figure 1(c), it is observed that when the credits and penalties are equal in magnitude in opposite direction, the average performance of manager is increasing function of the credits $(C)$ when there is only one option for each task. However the average performance of manager remains zero, when there are only two options for each task of the management. The average performance of the manager is a decreasing function of " $C$ " when $(C=-D)$ and the number of options for each task are more than or equal to " 3 ". Moreover, there is a negative performance on average, when there are more than two options for each managerial task.

From Table 2, it is observed that the variability in the performance is an increasing function of the credits $(C)$ for all categories of decision making problems when $C>1 ; D=-1 / C$. From Table 2 and Figure 2(a), it is 
Table 1. Expected scores for manager's performance.

\begin{tabular}{|c|c|c|c|c|c|c|c|c|c|c|c|c|}
\hline $\mathrm{R}$ & $\mathrm{D}$ & E1 & E2 & E3 & E4 & E5 & E6 & E7 & E8 & E9 & E10 & TS \\
\hline 2 & $(-1 / K)$ & 20 & 7.50 & 4.44 & 3.13 & 2.40 & 1.94 & 1.63 & 1.41 & 1.23 & 1.10 & 44.79 \\
\hline 4 & do & 40 & 17.50 & 11.11 & 8.13 & 6.40 & 5.28 & 4.49 & 3.91 & 3.46 & 3.10 & 103.37 \\
\hline 6 & do & 60 & 27.50 & 17.78 & 13.13 & 10.40 & 8.61 & 7.35 & 6.41 & 5.68 & 5.10 & 161.95 \\
\hline 8 & do & 80 & 37.50 & 24.44 & 18.13 & 14.40 & 11.94 & 10.20 & 8.91 & 7.90 & 7.10 & 220.53 \\
\hline 10 & do & 100 & 47.50 & 31.11 & 23.13 & 18.40 & 15.28 & 13.06 & 11.41 & 10.12 & 9.10 & 279.10 \\
\hline 2 & $(-1 / \mathrm{R})$ & 20 & 7.50 & 3.33 & 1.25 & 0.00 & -0.83 & -1.43 & -1.88 & -2.22 & -2.50 & 23.22 \\
\hline 4 & do & 40 & 18.75 & 11.67 & 8.13 & 6.00 & 4.58 & 3.57 & 2.81 & 2.22 & 1.75 & 99.48 \\
\hline 6 & do & 60 & 29.17 & 18.89 & 13.75 & 10.67 & 8.61 & 7.14 & 6.04 & 5.19 & 4.50 & 163.95 \\
\hline 8 & do & 80 & 39.38 & 25.83 & 19.06 & 15.00 & 12.29 & 10.36 & 8.91 & 7.78 & 6.88 & 225.48 \\
\hline 10 & do & 100 & 49.50 & 32.67 & 24.25 & 19.20 & 15.83 & 13.43 & 11.63 & 10.22 & 9.10 & 285.83 \\
\hline 2 & $(-\mathrm{R})$ & 20 & 0.00 & -6.67 & -10.00 & -12.00 & -13.33 & -14.29 & -15.00 & -15.56 & -16.00 & -82.84 \\
\hline 4 & do & 40 & 0.00 & -13.33 & -20.00 & -24.00 & -26.67 & -28.57 & -30.00 & -31.11 & -32.00 & -165.68 \\
\hline 6 & do & 60 & 0.00 & -20.00 & -30.00 & -36.00 & -40.00 & -42.86 & -45.00 & -46.67 & -48.00 & -248.52 \\
\hline 8 & do & 80 & 0.00 & -26.67 & -40.00 & -48.00 & -53.33 & -57.14 & -60.00 & -62.22 & -64.00 & -331.37 \\
\hline 10 & do & 100 & 0.00 & -33.33 & -50.00 & -60.00 & -66.67 & -71.43 & -75.00 & -77.78 & -80.00 & -414.21 \\
\hline 0.1 & $(-1 / R)$ & 1 & -49.50 & -66.33 & -74.75 & -79.80 & -83.17 & -85.57 & -87.38 & -88.78 & -89.90 & -704.17 \\
\hline 0.3 & do & 3 & -15.17 & -21.22 & -24.25 & -26.07 & -27.28 & -28.14 & -28.79 & -29.30 & -29.70 & -226.91 \\
\hline 0.4 & do & 4 & -10.50 & -15.33 & -17.75 & -19.20 & -20.17 & -20.86 & -21.38 & -21.78 & -22.10 & -165.06 \\
\hline 0.6 & do & 6 & -5.33 & -9.11 & -11.00 & -12.13 & -12.89 & -13.43 & -13.83 & -14.15 & -14.40 & -100.28 \\
\hline 0.8 & do & 8 & -2.25 & -5.67 & -7.38 & -8.40 & -9.08 & -9.57 & -9.94 & -10.22 & -10.45 & -64.96 \\
\hline
\end{tabular}

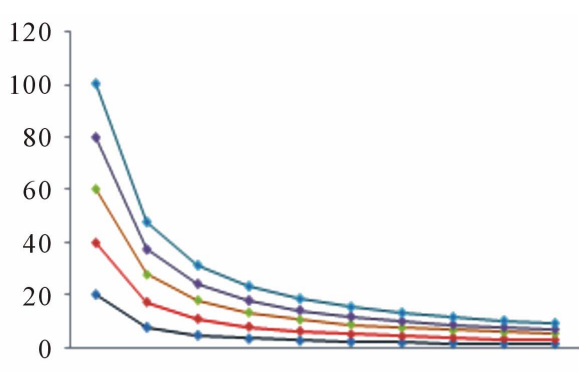

E1 E2 E3 E4 E5 E6 E7 E8 E9 E10

(a)

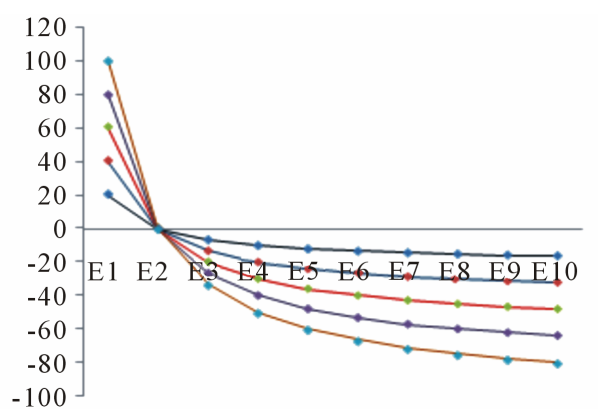

(c)
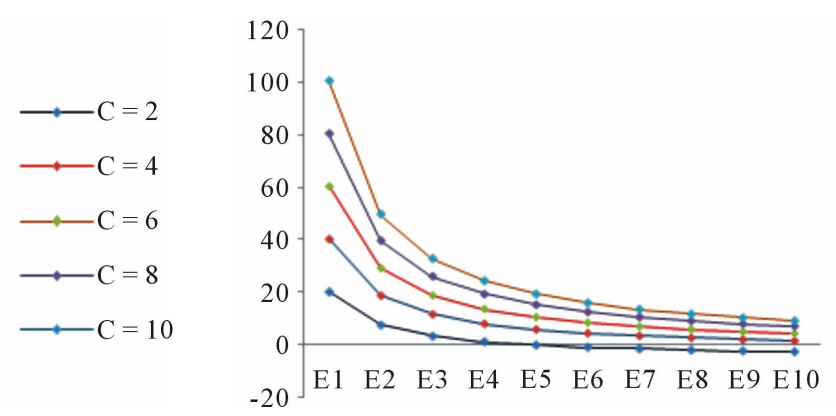

(b)

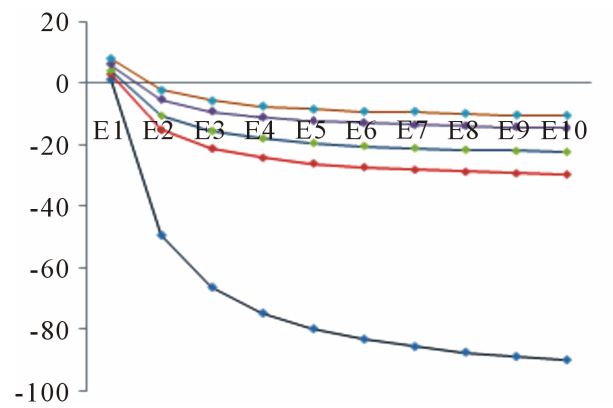

(d)

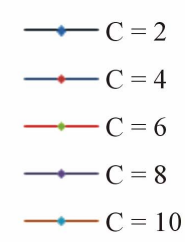

Figure 1. Total expected scores for varying values of (a) $C$ and $D=-1 / k$; (b) $C$ and $D=-1 / C$; (c) $C$ and $D=-(C)$; (d) $C(<1)$ and $D=-1 / C$. Total expected scores for different values of $A_{j}$ (number of tasks), $C$ (Credit Points), $D$ (penalty points); varying values of $A_{j}$ 's for $j=1,2, \cdots, i, i=10$. 
Table 2. Variability scores for manager's performance.

\begin{tabular}{|c|c|c|c|c|c|c|c|c|c|c|}
\hline $\mathrm{C}$ & $\mathrm{D}$ & V1 & $\mathrm{V} 2$ & V3 & V4 & V5 & V6 & V7 & V8 & V9 \\
\hline 1 & $-1 / \mathrm{i}$ & 118.75 & 103.70 & 87.89 & 75.52 & 65.97 & 58.48 & 52.47 & 47.55 & 43.47 \\
\hline 4 & Do & 1318.75 & 1148.15 & 959.77 & 814.72 & 704.86 & 619.99 & 552.86 & 498.58 & 453.87 \\
\hline 9 & Do & 6318.75 & 5555.56 & 4662.89 & 3966.72 & 3436.34 & 3025.24 & 2699.34 & 2435.48 & 2217.87 \\
\hline 16 & Do & 19618.75 & 17325.93 & 14572.27 & 12411.52 & 10760.42 & 9478.30 & 8460.67 & 7636.03 & 6955.47 \\
\hline 1 & $-1 / \mathrm{c}$ & 200.00 & 311.11 & 450.00 & 608.00 & 777.78 & 955.10 & 1137.50 & 1323.46 & 1512.00 \\
\hline 4 & do & 1254.69 & 1123.61 & 959.77 & 833.00 & 738.72 & 668.11 & 614.55 & 573.46 & 541.69 \\
\hline 9 & do & 6125.93 & 5446.91 & 4598.15 & 3926.52 & 3411.52 & 3011.04 & 2693.06 & 2435.48 & 2223.11 \\
\hline 16 & do & 19250.29 & 17111.89 & 14438.89 & 12322.06 & 10697.21 & 9432.06 & 8426.10 & 7609.92 & 6935.73 \\
\hline 1 & $-\mathrm{c}$ & 200.00 & 311.11 & 450.00 & 608.00 & 777.78 & 955.10 & 1137.50 & 1323.46 & 1512.00 \\
\hline 4 & do & 3200.00 & 4977.78 & 7200.00 & 9728.00 & 12444.44 & 15281.63 & 18200.00 & 21175.31 & 24192.00 \\
\hline 9 & do & 16200.00 & 25200.00 & 36450.00 & 49248.00 & 63000.00 & 77363.27 & 92137.50 & 107200.00 & 122472.00 \\
\hline 16 & do & 51200.00 & 79644.44 & 115200.00 & 155648.00 & 199111.11 & 244506.12 & 291200.00 & 338804.94 & 387072.00 \\
\hline 0.2 & $-1 / \mathrm{c}$ & 1928.00 & 5047.11 & 8946.00 & 13233.92 & 17737.78 & 22372.90 & 27093.50 & 31872.79 & 36694.08 \\
\hline 0.4 & do & 530.75 & 1305.11 & 2273.06 & 3339.68 & 4461.53 & 5617.10 & 6794.70 & 7987.46 & 9191.07 \\
\hline 0.6 & do & 285.33 & 624.00 & 1047.33 & 1515.95 & 2010.37 & 2520.71 & 3041.50 & 3569.51 & 4102.72 \\
\hline 0.8 & do & 215.19 & 399.61 & 630.14 & 887.72 & 1161.22 & 1444.68 & 1734.77 & 2029.46 & 2327.47 \\
\hline
\end{tabular}

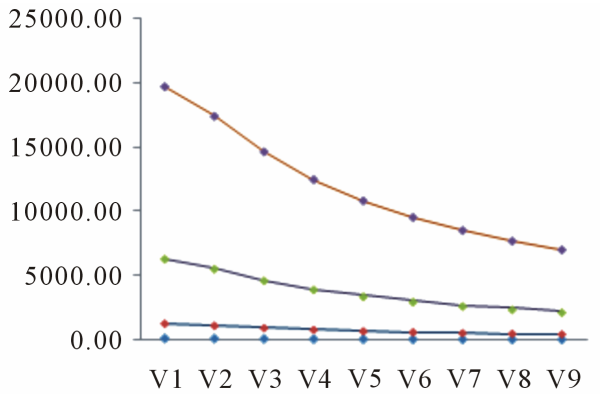

(a)

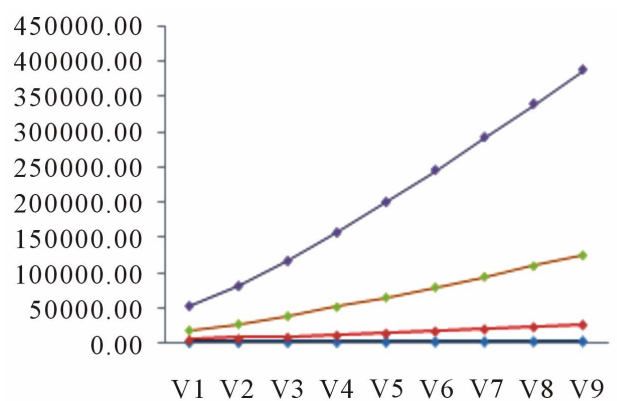

(c)

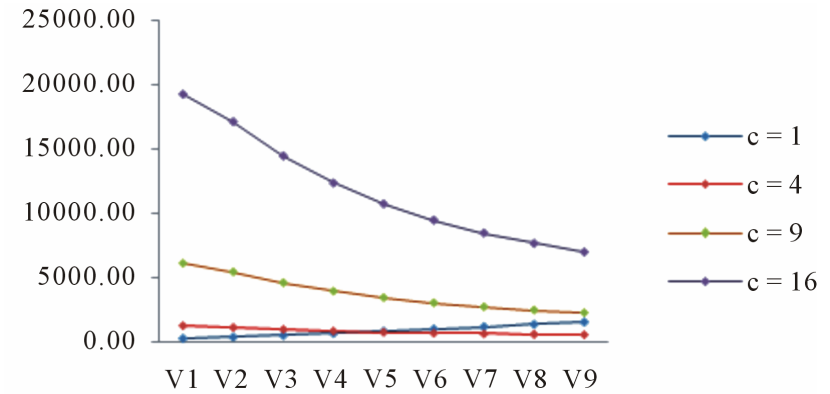

(b)

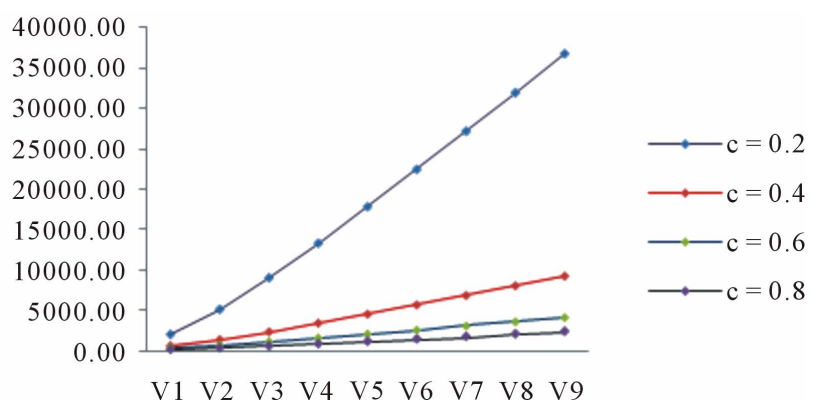

(d)

Figure 2. Graph for variability in the performance for varying values of (a) $C$ and $D=-1 / K$; (b) $C$ and $D=-1 / C$; (c) $C$ and $D$ $=-(C) ;(\mathrm{d}) C(<1)$ and $D=-1 / C$.

understand that the variances are decreasing functions of the number of options in each category of the task, when the number of tasks in each category are fixed for $D=-1 / C ; C>1$. From Table 2 and Figure 2(b), it is observed that the variances are decreasing functions of the number of available options in each category of the task, when the number of tasks in each category are fixed, for $C>1 ; D=-C$. From Table 2 and Figure 2(c), it is observed that the variabilities in manager's performance are decreasing functions of the number of available 
options to the manager in each task when $C<1$; $D=-1 / C$. Table 2 and Figure 2(d), reveals that the overall variabilities are decreasing functions as the number of available options to each task are monotonically decreasing at $C=2, D=-1 / C, D=-C$.

\section{REFERENCES}

[1] J. F. Kottas and H.-S. Lau, "A Four-Moments Alternative to Simulation for a Class of Stochastic Management Models," Management Science, Vol. 28, No. 7, 1982, pp. 749-758. doi: $10.1287 / \mathrm{mnsc}$.28.7.749

[2] R. Agarwal, "Concurrency Control Performance Modelling Alternatives and Implications," ACM Transactions on Database Systems, Vol. 12, No. 4, 1987, pp. 609-654.

[3] E. Fernández-Gaucherand, S. Jain, H. L. Lee, A. G. Rao and M. R. Rao, "Improving Productivity by Periodic Performance Evaluation: A Bayesian Stochastic Model," Management Science, Vol. 41, No. 10, 1995, pp. 16691678. doi: $10.1287 / \mathrm{mnsc} .41 .10 .1669$

[4] K. W. Al-Rawi, "A Suggested Mathematical Model for Project Financial Performance Evaluation," Journal of King Abdulaziz University Economics and Administration, Vol. 17, No. 1, 2003, pp. 19-29.

[5] S. Basak, A. Shapiro and L. Teplá, "Risk Management with Benchmarking," Management Science, Vol. 52, No. 4, 2006, pp. 542-557. doi: $10.1287 / \mathrm{mnsc} .1050 .0476$
[6] D. Kusic, et al., "Approximation Modeling for the Online Performance Management of Distributed Computing Systems," IEEE Transactions on Systems, Man, and Cybernetics-Part-B: Cybernetics, Vol. 38, No. 5, 2008, pp. 1221-1233

[7] C. C. Yee, et al., "Performance Appraisal System Using Multifactorial Evaluation Model," World Academy of Science, Engineering and Technology, Vol. 53, 2009, pp. 231-235.

[8] A. L. Cesar, et al., "Perfromance Analysis of ResourceConstrained Business Processes: A Formal Approach Based on Stochastic Petri Nets," 28 March 2009, pp. 129.

[9] M. B. Sheikh, et al., "A Bayesian Approach to Online Performance Modeling for Database Appliances Using Gaussian Models," ACM, New York, 2011.

[10] M. Kihl, et al., "Performance Modeling of Database Servers in a Telecommunication Service Management System," IARIA 7th International Conference on Digital Telecommunications (ICDT 2012), Chamonix, 29 April4 May 2012.

http://lup.lub.lu.se/luur/download?func=downloadFile\&re cordOId $=2539774 \&$ fileOId $=2539775$

[11] J.-Z. Sun and J. Sauvola, "Modeling Techniques for Simulation Based Performance Evaluation of Management Schemes". www.mediateam.oulu.fi/publications/pdf/613.pdf. 